\title{
Analysis on Dg's Connection in a Developed Model of Doubly-Fed Wind Energy System
}

\author{
G.Radhakrishnan \\ Assistant professor \\ Electrical Engineering \\ RVS College of Engg and Tech, \\ Coimbatore, Tamilnadu, India.
}

\author{
G.R.Krishnakumar, R.Manju and S.Nandini \\ UG Scholar- Electrical Engineering \\ RVS College of Engg and Tech \\ Coimbatore, Tamilnadu, India.
}

\begin{abstract}
In recent years, wind energy has become one of the most important and promising sources of renewable energy, which demands additional transmission capacity and better means of maintaining system reliability. The evolution of technology related to wind systems industry leaded to the development of a generation of variable speed wind turbines that present many advantages compared to the fixed speed wind turbines. These wind energy conversion systems are connected to the grid through Voltage Source Converters (VSC) to make variable speed operation possible. The stator of the generator is directly connected to the grid while the rotor is connected through a back-to-back converter which is dimensioned to stand only a fraction of the generator rated power.

To harness the wind power efficiently the most reliable system in the present era is grid connected doubly fed induction generator. The rotor side converter (RSC) of DFIG usually provides active and reactive power control of the machine while the grid-side converter (GSC) keeps the voltage of the DC-link constant. The additional freedom of reactive power generation by the GSC is usually not used due to the fact that it is more preferable to do so using the RSC. However, within the available current capacity the GSC can be controlled to participate in reactive power generation in steady state as well as during low voltage periods. The GSC can supply the required reactive current very quickly while the RSC passes the current through the machine resulting in a delay. Both converters can be temporarily overloaded, so the DFIG is able to provide a considerable contribution to grid voltage support during short circuit periods.

In this paper we focus on analysing a wind turbine system using MATLAB SimPower Systems. The machine used was a doubly fed induction generator (DFIG).As protection against short circuit transients, the crowbar protection was modelled.
\end{abstract}

General terms: DFIG, Fault Ride Through, Grid.

\section{INTRODUCTION}

\subsection{Utilization of Wind Turbines}

Mankind has used the wind as a source of energy for several thousands of years. It was one of the most utilized sources of energy together with hydro power during the seventeenth and eighteenth centuries. By the end of the 19th century the first experiments were carried out on the use of windmills for generating electricity. Electricity is traded like any other commodity on the market and there are, therefore, standards which describe its quality. In the case of electric power they are commonly known as the Power Quality standards. Any device connected to the electric grid must fulfil these standards and this is particularly interesting and important issue to be considered in the case of wind power installations, since the stochastic nature of wind and standardized parameters of electricity are joined together there. A mathematical model of a wind turbine capable of predicting its interaction with the grid is thus an important topic.

\subsection{Need of DFIG}

In a doubly-fed induction generator, the mechanical power generated by the wind turbine is transformed into electrical power by an induction generator and is fed into the main grid through the stator and the rotor windings. The rotor winding is connected to the main grid by self commutated AC/DC converters allowing controlling the slip ring voltage of the induction machine in magnitude and phase angle [1].

In contrast to a conventional, singly-fed induction generator, the electrical power of a doubly-fed induction machine is independent from the speed. Therefore, it is possible to realize a variable speed wind generator allowing adjusting the mechanical speed to the wind speed and hence operating the turbine at the aerodynamically optimal point for a certain wind speed range.

\subsection{Indirect Grid Connection}

The advantage of indirect grid connection is that it is possible to run the wind turbine at variable speed.

- The primary advantage is that gusts of wind can be allowed to make the rotor turn faster, thus storing part of the excess energy as rotational energy until the gust is over. Obviously, this requires an intelligent control strategy, to differentiate between gusts and higher wind speed in general.

- The secondary advantage is that with power electronics one may control reactive power (i.e. the phase shifting of current relative to voltage in the $\mathrm{AC}$ grid), so as to improve the power quality in the weak electrical grid.

\subsection{Objective}

Withstanding grid faults becomes an obligation for the bulk wind generation units connected to the transmission network and it is highly desired for distribution wind generators. The penetration of wind generation into power systems is rapidly increasing since it is clean, renewable and having minimal running cost requirements. Therefore, the mode with response of bulk wind generators to the transient grid faults can lead to unhealthy system operation and in due course affect the system stability. Doubly-Fed Induction by Generator (DFIG) technology is widely used in large and the modern wind turbines since it permits variable speed operation at reasonable cost and provides a reactive power control. With the increasing penetration of wind turbines employing DFIG, it becomes a necessity to investigate their 
behavior during transient disturbances and support them with fault ride through capabilities.

This capability means that all generation plants, including wind generation, should have the ability to remain connected during faults (outside their protection zone) and voltage dip conditions within certain limits. A bypass resistorset known as crowbar that is connected in the event of fault to the rotor terminals in order to improve the DFIG fault ride through capabilities were analyzed.

\section{CONCEPT OF DFIG}

\subsection{Operating Principle}

Wind turbines of DFIG-type show behaviour close to that of the traditional induction machine due to their technical similarities. There are however two significant differences: One; when bypass resistors in the crow bar is connected resistance can no longer be neglected, and two; the DFIG slip can be far from zero, whereas the induction machine always operate close to zero slip. There are also some clear differences due to the controllability of the rotor current in a DFIG, since the electrical torque is no longer governed by the slip.

The prime mover, consisting of a pitch-angle controlled wind turbine, the shaft and the gear-box drives a slip-ring induction generator. The stator of the DFIG is directly connected to the grid; the slip-rings of the rotor are fed by self-commutated converters. These converters allow controlling the rotor voltage in magnitude and phase angle and can therefore be used for active- and reactive power control.

The physical properties of the stator in the DFIG remain the same, but the rotor circuit is fed from the generator side converter, by which the rotor current is fully dictated. When the voltage drops at the generator terminals, the rotor current from the converter increases in a compensation effort to stabilize the active power output from the turbine and together with the passive response of the stator-circuit, the resulting transient currents can reach 5 p.u.

With the rotor side converter, the situation is different due to protective practices in DFIG. Whether the DFIG is totally disconnected from the system or not, depends on the actual deepness of the voltage sag and on the applied protection philosophy. The correct modeling of the rotor bypass, usually called "crow bar protection", is essential to assess voltage stability of large farms during faults in the transmission or distribution network.

This situation cannot last very long without any controlling action or a special design to cope with the situation. LVRT-strategies can be implemented either on the stator or the rotor side of the generator [2]. Over-sizing of the converter transistors will ensure that the set point for controlling action can be delayed, but does not change the physical situation very much.

Indeed, the basic concept is to interpose a frequency converter between the variable frequency induction generator and fixed frequency grid. The DC capacitor linking stator- and rotor-side converters allows the storage of power from induction generator for further generation. To achieve full control of grid current, the DC-link voltage must be boosted to a level higher than the amplitude of grid line-to-line voltage. As a result, the machine can be controlled as a generator or a motor in both super and sub-synchronous operating modes realizing four operating modes [3].

\subsubsection{Wound Rotor Induction Motors}

A wound rotor induction motor has a stator like the squirrel cage induction motor, but a rotor with insulated windings brought out via slip rings and brushes. However, no power is applied to the slip rings (Figure.2.1). This resistance is shorted out once the motor is started to make the rotor look electrically like the squirrel cage counterpart [4].

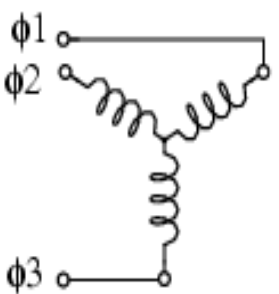

Stator

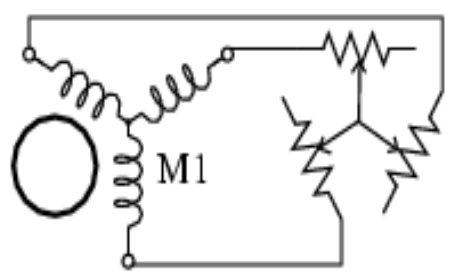

Rotor Start resistance
Figure.2.1. Wound rotor induction motor.

Figure.2 shows that by increasing the rotor resistance from $R_{0}$ to $R_{1}$ to $R_{2}$, the breakdown torque peak is shifted left to zero speed. The peak of this torque is much higher than the starting torque available with no rotor resistance $\left(\mathrm{R}_{0}\right)$ Slip is proportional to rotor resistance, and pullout torque is proportional to slip. Thus, high torque is produced while starting breakdown torque peak is shifted to zero speed by increasing rotor resistance.

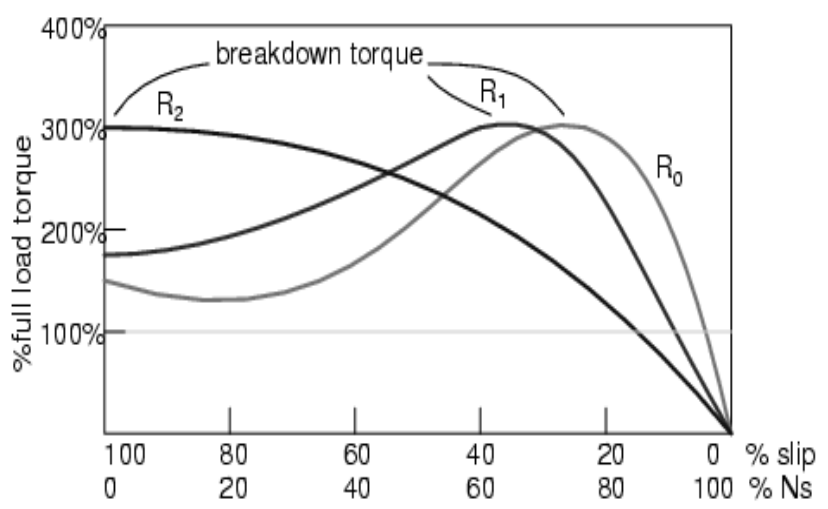

Figure.2.2. Torque Vs Speed characteristics.

The resistance decreases the torque available at full running speed. But that resistance is shorted out by the time the rotor is started. A shorted rotor operates like a squirrel cage rotor. Heat generated during starting is mostly dissipated external to the motor in the starting resistance. The complication and maintenance associated with brushes and slip rings is a disadvantage of the wound rotor as compared to the simple squirrel cage rotor.

This motor is suited for starting high inertial loads. A high starting resistance makes the high pull out torque available at zero speed. For comparison, a squirrel cage rotor only exhibits pull out (peak) torque at $80 \%$ of its' synchronous speed.

\subsubsection{Speed Control}

Motor speed may be varied by putting variable resistance back into the rotor circuit. This reduces rotor current and speed. A higher resistance at $\mathrm{R}_{3}$ reduces the speed further. Speed regulation is poor with respect to changing torque loads. This speed control technique is only useful over a range of $50 \%$ to $100 \%$ of full speed. 


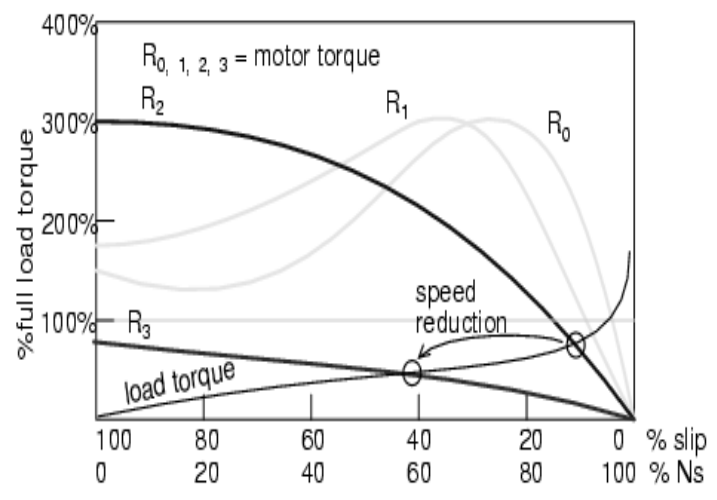

Figure.2.3. Rotor resistance controls speed of wound rotor induction motor.

\subsubsection{Doubly-Fed Induction Generator}

A wound rotor induction motor may also act as a generator when driven above the synchronous speed. Since there are connections to both the stator and rotor, such a machine is known as a doubly-fed induction generator (DFIG).

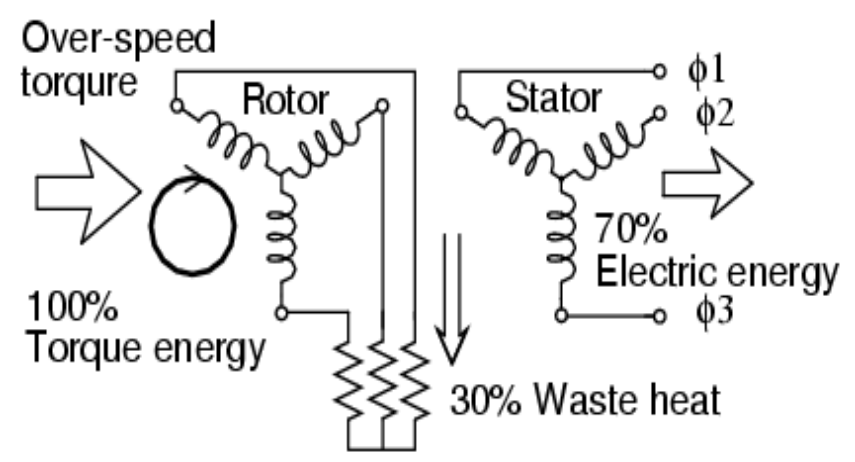

Figure.2.4. Rotor resistance allows over-speed of doubly-fed induction generator.

If the generator over-speeds, resistance placed in the rotor circuit will absorb excess energy while the stator feeds constant $60 \mathrm{~Hz}$ to the power line (Figure. 2.4). In the case of under-speed, negative resistance inserted into the rotor circuit can make up the energy deficit, still allowing the stator to feed the power line with $60 \mathrm{~Hz}$ power [6].

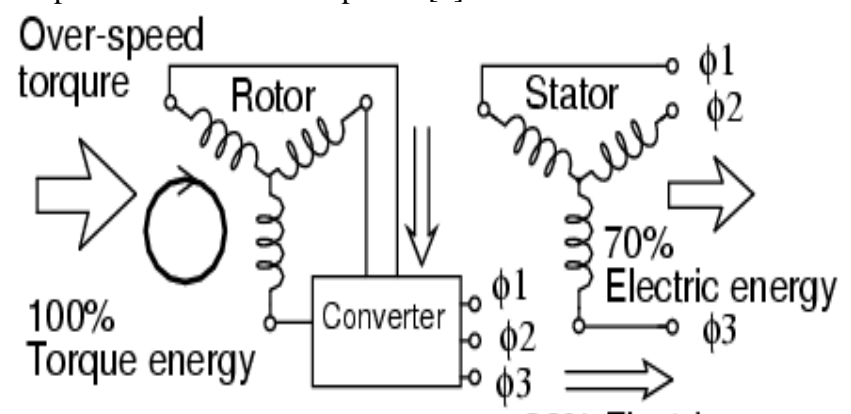

$30 \%$ Electric energy

Figure.2.5. Converter recovers energy from rotor of doublyfed induction generator.

In actual practice, the rotor resistance may be replaced by a converter (Figure. 2.5) absorbing power from the rotor, and feeding power into the power line instead of dissipating it. This improves the efficiency of the generator.

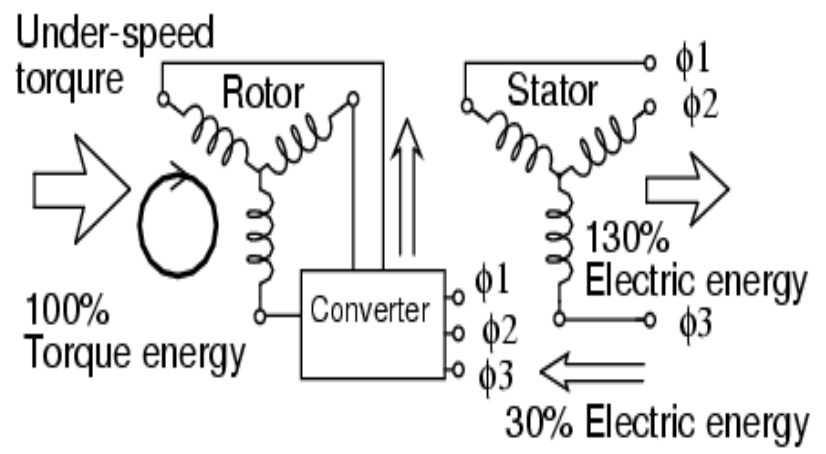

Figure.2.6. Converter borrows energy from power line for rotor of

doubly fed induction generator, allowing it to function well under synchronous speed.

The converter may "borrow" power from the line for the under-speed rotor, which passes it on to the stator. (Figure.2.6) The borrowed power, along with the larger shaft energy, passes to the stator which is connected to the power line. The stator appears to be supplying $130 \%$ of power to the line. Keep in mind that the rotor "borrows" $30 \%$, leaving, leaving the line with $100 \%$ for the theoretical lossless DFIG.

\subsection{Comparison of DFIG}

Wind turbines can operate with either fixed speed (actually within a speed range about $1 \%$ ) or variable speed. For fixed-speed wind turbines, the generator (induction generator) is directly connected to the grid. Since the speed is almost fixed to the grid frequency, and most certainly not controllable, it is not possible to store the turbulence of the wind in form of rotational energy. Therefore, for a fixed-speed system the turbulence of the wind will result in power variations, and thus affect the power quality of the grid.

For a variable-speed wind turbine the generator is controlled by power electronic equipment, which makes it possible to control the rotor speed. In this way the power fluctuations caused by wind variations can be more or less absorbed by changing the rotor speed and thus power variations originating from the wind conversion and the drive train can be reduced. Hence, the power quality impact caused by the wind turbine can be improved compared to a fixedspeed turbine [7].

The rotational speed of a wind turbine is fairly low and must therefore be adjusted to the electrical frequency. This can be done in two ways: with a gearbox or with the number of pole pairs of the generator. The number of pole pairs sets the mechanical speed of the generator with respect to the electrical frequency and the gearbox adjusts the rotor speed of the turbine to the mechanical speed of the generator.

In this section the following wind turbine systems will be presented:

1. Fixed-speed wind turbine with an induction generator.

2. Variable-speed wind turbine,

a. Equipped with a cage-bar induction generator or synchronous generator

b. Equipped with multiple-pole synchronous generator or multiple-pole permanent-magnet synchronous generator

3. Variable-speed wind turbine equipped with a doubly-fed induction generator.

\subsubsection{Fixed-Speed Wind Turbine}

For the fixed-speed wind turbine the induction generator is directly connected to the electrical grid according 
to Figure. 2.7. The rotor speed of the fixed-speed wind turbine is in principle determined by a gearbox and the pole-pair number of the generator.

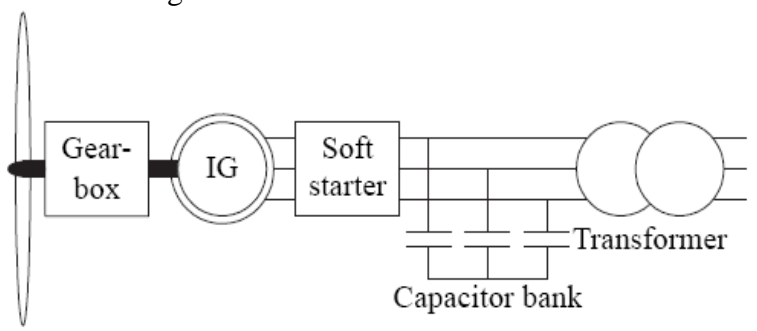

Figure.2.7. Fixed-speed wind turbine with an induction generator.

The fixed-speed wind turbine system has often two fixed speeds. This is complished by using two generators with different ratings and pole pairs, or it can be a generator with two windings having different ratings and pole pairs.

\subsubsection{Variable-Speed Wind Turbine}

The system presented in Figure. 2.8 consists of a wind turbine equipped with a converter connected to the stator of the generator. The generator could either be a cage-bar induction generator or a synchronous generator. The gearbox is designed so that maximum rotor speed corresponds to rated speed of the generator [5].

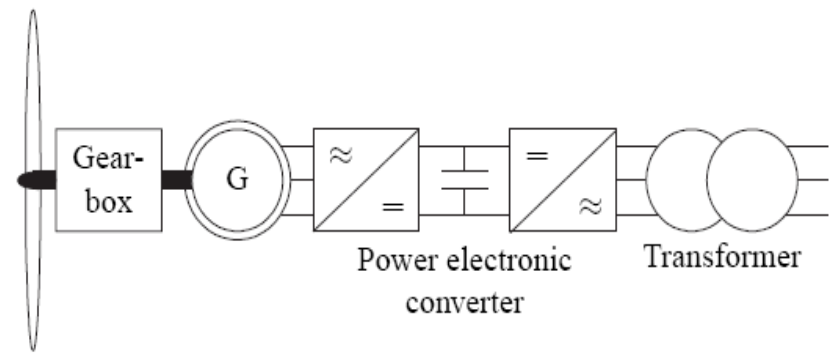

Figure.2.8. Variable-speed wind turbine with a synchronous/induction generator.

Synchronous generators or permanent-magnet synchronous generators can be designed with multiple poles which imply that there is no need for a gearbox (Figure. 2.9). Since this "full-power" converter/generator system is commonly used for other applications, one advantage with this system is its well-developed and robust control.

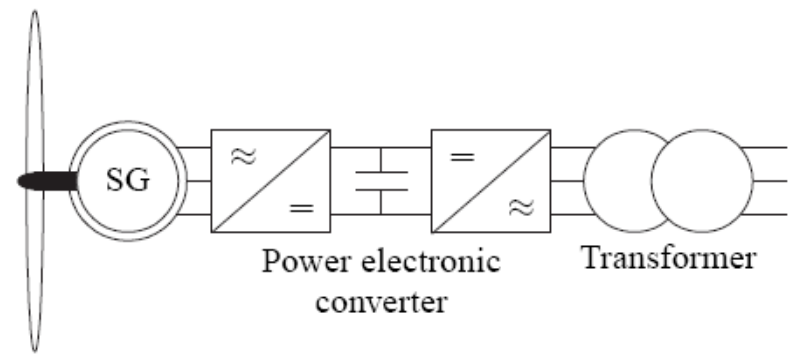

Figure.2.9. Variable-speed direct-driven (gear-less) wind turbine with a synchronous generator.

\subsubsection{Variable-Speed Wind Turbine with Doubly- Fed Induction Generator}

This system (Figure.2.10) consists of a wind turbine with doubly-fed induction generator. This means that the stator is directly connected to the grid while the rotor winding is connected via slip rings to a converter. This system has recently become very popular as generators for variable-speed wind turbines [4].

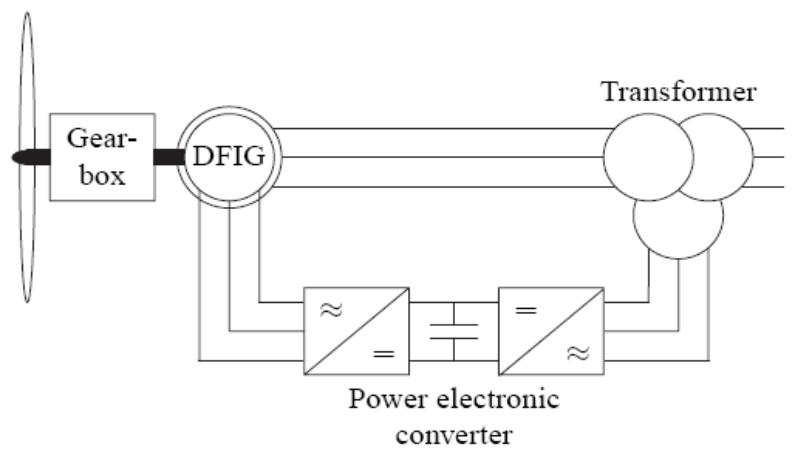

Figure.2.10. Variable-speed wind turbine with a doubly-fed induction generator (DFIG).

There exists a variant of the DFIG method that uses controllable external rotor resistances (compare to slip power recovery). Some of the drawbacks of this method are that energy is unnecessary dissipated in the external rotor resistances and that it is not possible to control the reactive power.

\subsection{Torque Speed Characteristics of DFIG}

The speed-torque characteristics of the DFIG system can be seen in Figure. 2.11. As also seen in the figure, the DFIG can operate both in motor and generator operation with a rotor-speed range of $\pm \mathrm{del} \omega_{\mathrm{r}}^{\max }$ around the synchronous speed, $\boldsymbol{w}_{1}$.

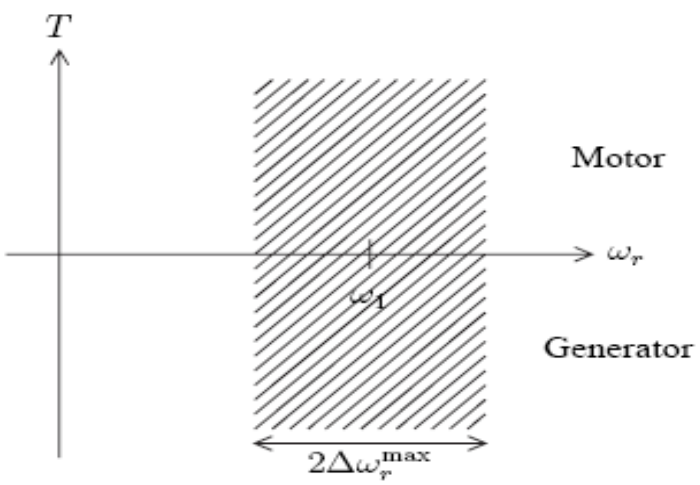

Figure.2.11. Torque speed characteristics of a DFIG.

A typical application, as mentioned earlier, for DFIG is wind turbines, since they operate in a limited speed range of approximately $\pm 30 \%$.

\section{DFIG WIND TURBINE SYSTEM}

\subsection{Importance of DFIG}

DFIGs are variable speed generators with advantages compared to other solutions. Fixed speed generators and induction generators had the disadvantage of having low power efficiencies at most speeds. To improve the efficiency, controlled power electronics converters are commonly used.

Voltage source inverters are used to convert the voltage magnitude and frequency to match the grid values. This implies that the converter is dimensioned to suit the rotor parameters. This makes the system more economical than using a full power rated converter in a series configuration [5]. 
The drive system operates in four quadrants. This implies that a bidirectional flow of power is possible. The possibility of supplying and consuming reactive power enables the generator system to act as a power factor compensator. By the control of the back to back inverters, the slip may be controlled. In the case of the squirrel cage induction machine, for example, as the rotor cannot be driven, the slip only depends on the stator and load inputs.

As for synchronous machines, a relatively large torque may cause the machine to oscillate. The DFIG does not pose any synchronisation problems. To observe the system and the flow of active and reactive power, a dynamic model is needed. The machine may be simulated as an induction machine having 3 phase supply in the stator and three phase supply in the rotor.

In Figure.3.1 a basic layout of a DFIG wind turbine system is shown. The rotor circuit is connected through slip rings to the back to back converter arrangement controlled by PWM strategies. The voltage magnitude and power direction between the rotor and the supply may be varied by controlling the switch impulses that drive the IGBTs.

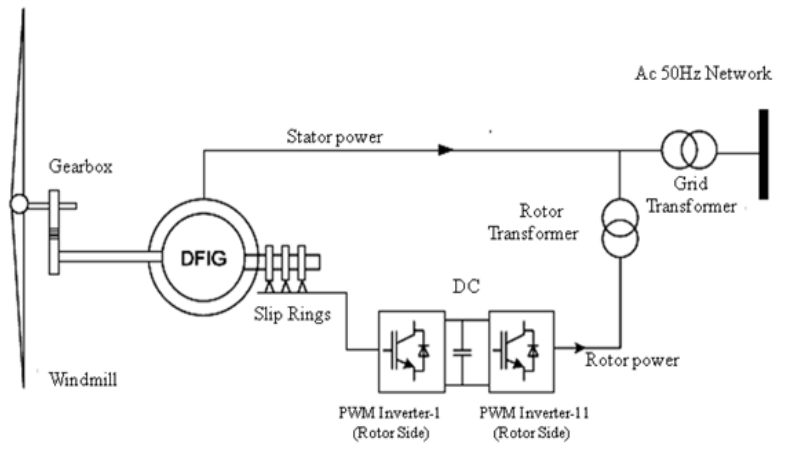

Figure.3.1 DFIG wind turbine System

Back to back converters consist of two voltage source converters (ac-dc-ac) having a dc link capacitor connecting them. The generator side converter takes the variable frequency voltage and converts it into dc voltage. The grid side converter has the ac voltage from the dc link as input and voltage at grid parameters as output.

The gearbox has the role of matching the speed between the blades and the rotor. The transformer couples the generator to the grid, adjusts the voltage of the machine to that of the grid. This is only a typical example of the DFIG system layout.

The stator is connected directly to the grid. The rotor on the other hand needs a step down transformer in order to connect to the grid. For a normal generation regime, the energy obtained by processing the wind speed as an input is fed into the network by both the stator and the rotor.

\subsection{Stator to Rotor Turns Ratio}

Since the losses in the power electronic converter depend on the current through the valves, it is important to have a stator-to-rotor turns ratio of the DFIG that minimizes the rotor current without exceeding the maximum available rotor voltage. In Figure.3.2 a transformer is placed between the rotor circuit and the converter. The transformer is to highlight and indicate the stator-to-rotor turns ratio, but it does not exist in reality [3].

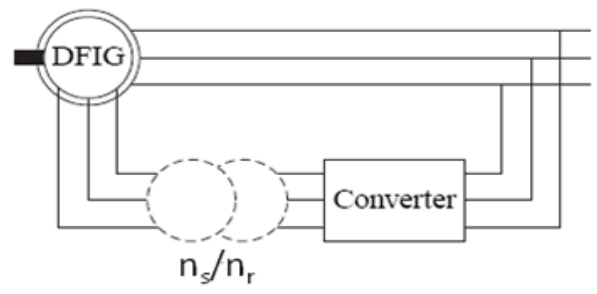

Figure.3.2. Stator-to-rotor turns ratio indicated with a "virtual" transformer.

For example, if the stator-to-rotor turns ratio, $n_{\mathrm{s}} / \mathrm{n}_{\mathrm{r}}$, is 0.4 , the rotor current is approximately 0.4 times smaller than the stator current, if the magnetizing current is neglected.

\section{VARIABLE SPEED WIND TURBINE 4.1 Concept}

During the last few years, variable speed wind turbines have become the most dominating type of yearly installed wind turbines. The increased interest in the variable speed wind turbines is due to their very attractive features, given by the presence of the power converter, with respect to both the wind turbine itself as well as to more onerous grid requirements.

The variable speed wind turbines have a more complicated electrical system than the fixed speed wind turbines. They are typically equipped with an induction or synchronous generator and a power converter. The presence of the power converter makes the variable speed operation itself possible. The variable speed wind turbines can therefore be designed to achieve maximum power coefficient over a wide range of wind speeds.

The power converter controls the generator speed in such a way that the power fluctuations caused by wind variations are more or less absorbed by changing the generator speed and implicitly the wind turbine rotor speed. Seen from the wind turbine point of view, the most important advantages of the variable speed operation compared to the conventional fixed speed operation are:

- Reduced mechanical stress on the mechanical components such as shaft and gear-box - the high inertia of the wind turbine is used as a flywheel during gusts, i.e. the power fluctuations are absorbed in the mechanical inertia of the wind turbine.

- Increased power capture - due to the variable speed feature, it is possible to continuously adapt (accelerate or decelerate) the rotational speed of the wind turbine to the wind speed, in such a way that the power coefficient is kept at its maximum value.

- Reduced acoustical noise - low speed operation is possible at low power conditions (lower wind speeds).

All these attractive features make the variable speed wind turbine concept very popular despite some few disadvantages, such as losses in power electronics and increased installation cost due to the power converter [4]. Currently, there are two dominating groups of variable speed wind turbine concepts on the market:

- Full variable speed concept - where the generator stator is interconnected to the grid through a full-scale power converter. The generator can be synchronous (WRSG or PMSG) or induction generator (WRIG).

- Limited variable speed concept - where the generator stator is connected to the grid. The rotor frequency and thus the rotor speed are controlled. The generator is a wound rotor induction generator (WRIG). There are two such wind turbine concepts: 
$\checkmark$ The variable generator rotor resistance concept, where the rotor is connected to an external optically controlled resistance, whose size defines the range of the variable speed (typically $0-10 \%$ above synchronous speed).

$\checkmark$ The doubly-fed induction generator (DFIG) concept, where the rotor is controlled by a partial scale power converter, whose size defines the range of the variable speed (typically $+/-30 \%$ around synchronous speed).

Out of all these variable speed wind turbine concepts, the concept with doubly-fed induction generator (DFIG) distinguishes itself as a very attractive option with a fast growing market demand.

\subsection{Variable Speed Wind Turbine Characteristics}

A wind turbine is characterised by its power speed characteristics. For a horizontal axis wind turbine, the amount of mechanical power $\mathrm{P}_{\text {mech }}$ that a turbine produces in steady state is given by:

$$
P_{\text {mech }}=(1 / 2) \rho \pi R^{2} U^{3} C_{p}(\theta, \lambda)
$$

where, $\rho$ is the air density, $\mathrm{R}$ the turbine radius, $\mathrm{u}$ the wind speed and $C_{p}(\theta, \lambda)$ is the power coefficient, which for pitch controlled wind turbines depends on both the pitch angle $\theta$ and the tip speed ratio $\lambda$. The tip speed ratio $\lambda$ is given by:

$$
\text { where, }
$$

$$
\lambda=\left(\omega_{\mathrm{rot}} \mathrm{R}\right) /(\mathrm{U})
$$

$\omega_{\text {rot }}$ denotes the rotor turbine speed.

The prime motivation for variable speed wind turbines at lower wind speeds is to adjust the rotor speed at changing wind speeds so that $\mathrm{C}_{\mathrm{p}}(\theta, \lambda)$ always is maintained at its maximum value [7]. The power coefficient $C_{p}(\theta, \lambda)$ has a maximum for a particular tip-speed ratio $\lambda_{\text {opt }}$ and pitch angle $\theta_{\text {opt }}$. This means that for extracting maximum power from a particular wind speed, the control strategy has to change the turbine rotor speed in such a way that the optimum tip speed ratio $\lambda_{\text {opt }}$ is always obtained. The maximum power a particular wind turbine can extract from the wind is a cubic function of the turbine optimum speed, as follows:

$$
\text { where, }
$$

$$
\mathrm{P}=\mathrm{K}_{\mathrm{opt}}\left[\omega_{\mathrm{rot}}^{\mathrm{opt}}\right]
$$

$$
\mathrm{K}_{\mathrm{opt}}=(1 / 2) \rho \pi \mathrm{R}^{2}\left(\mathrm{C}_{\mathrm{p}}^{\mathrm{max}} / \lambda^{3}{ }_{\text {opt }}\right)
$$

$\mathrm{K}_{\mathrm{opt}}$ depends on the turbine characteristics and the air density. Tracking the maximum power is the goal as long as the generated power is less than the rated power. At wind speeds higher than rated wind speed, the control strategy has to be changed so that the wind turbine no longer produces maximum power but only rated power. The blades are thus pitched to reduce the power coefficient $C_{p}(\theta, \lambda)$ and thereby to maintain the power at its rated value. Wind gusts are absorbed by rotor speed changes, the wind turbine's rotor behaving as energy storage.

The mechanical power is transformed in the generator into electrical power, the relation between them being given by:

$$
\text { where, }
$$

$$
\mathrm{P}_{\mathrm{el}}=\eta_{\mathrm{gen}} \mathrm{P}_{\mathrm{mec}}
$$

$\eta_{\text {gen }}$ is the generator efficiency.

The fundamental feature of the DFIG is that the power processed by the power converter is only a fraction of the total wind turbine power, and therefore its size, cost and losses are much smaller compared to a full-scale power converter used in the full variable speed concept.

\section{CROW-BAR PROTECTION}

For converter protection reasons, as a part of any fault ride through system, a crow bar is connected between the rotor and the rotor-side converter. If the rotor voltage exceeds a certain threshold, current thyristors in the crow bar will be activated and the current will pass through resistors, which are grounded on the downside. This action will prevent to high rotor currents and excessive DC-link voltage. The resulting voltage amplitude in the rotor circuit is determined by the crow bar resistors [7].

The crow bar resistors also act as an active power sink, burning off active power to mitigate rotor over-speeding. During the time the crow bar is activated, the generator works as a conventional induction generator with high rotor resistance. Several different chains of events can follow a crow bar action, and those are effectively the different LVRTstrategies.

One possibility is to overrate the IGBT modules in the converter to allow for an extended, voltage tolerance of the DC-link, another is the possibility to disconnect the rotor side converter but not the grid side converter and a third is to disconnect the stator and continue the active operation of both converters and the DC link. The main goal of the LVRTsystems regardless is instantaneous resumed active operation for the wind turbine after grid fault clearance.

\subsection{Survey of DFIG Fault-Ride Through Solution}

The usual approach to the problem of voltage dips has been to place a crowbar circuit connected to the rotor of the wind turbine. The crowbar short circuits the rotor when a voltage dip is detected and the power converter connected to the rotor is protected. Crowbar circuits may be anti-parallel thyristor crowbar, diode bridge crowbar or other more unusual configurations (Figure.2).

The diode bridge crowbar is usually preferred to the anti-parallel thyristor and the rest of configurations because it uses less thyristors and it is controlled more easily. Either when the voltage at the DC bus reaches its maximum value or when the limit rotor current is exceeded, the crowbar is activated, the rotor converter is disconnected from the rotor, and the rotor windings are short-circuited by the crowbar [8].

The crowbar remains connected to the rotor until stator is disconnected from the grid and the rotor currents disappear because there is no control on the turning off of thyristors. This is no longer acceptable under the new grid codes. New grid codes require that the wind farm remains connected to the grid during the voltage dip.

\subsection{New Solutions for Low Voltage Ride Through in Wind Turbines with DFIG-Active Crow-Bar \\ In order to remove the crowbar short as fast as} possible, the crowbar thyristors are substituted with fully controllable switches, namely IGBTs.During the crowbar active time, the rotor side converter is disconnected and there is no control on the generator. 


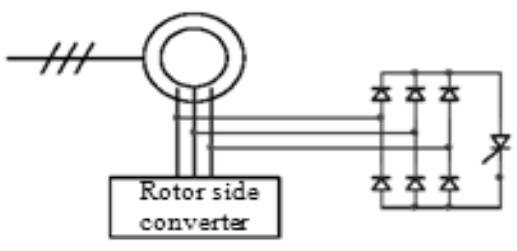

Figure 5.7.Typical crowbar circuit

When the crowbar is deactivated and the converter regains control, high current transients may take place and sometimes the crowbar is reactivated.

\section{SIMULATION MODEL}

\subsection{Wind Electric Energy Simulation with}

\section{Grid Connection}

Simulation study of a grid-connected wind farm using MATLAB/SIMULINK:

- Three-bus to five-bus AC system.

- Steady state analysis (power generation with respect to wind speed).
- Transient analysis (line-to-ground fault, line-to-line fault, and three phase-to-ground faults).

A demonstration of the DG can be built in the laboratory using the simplified model presented in this paper. The benefits of

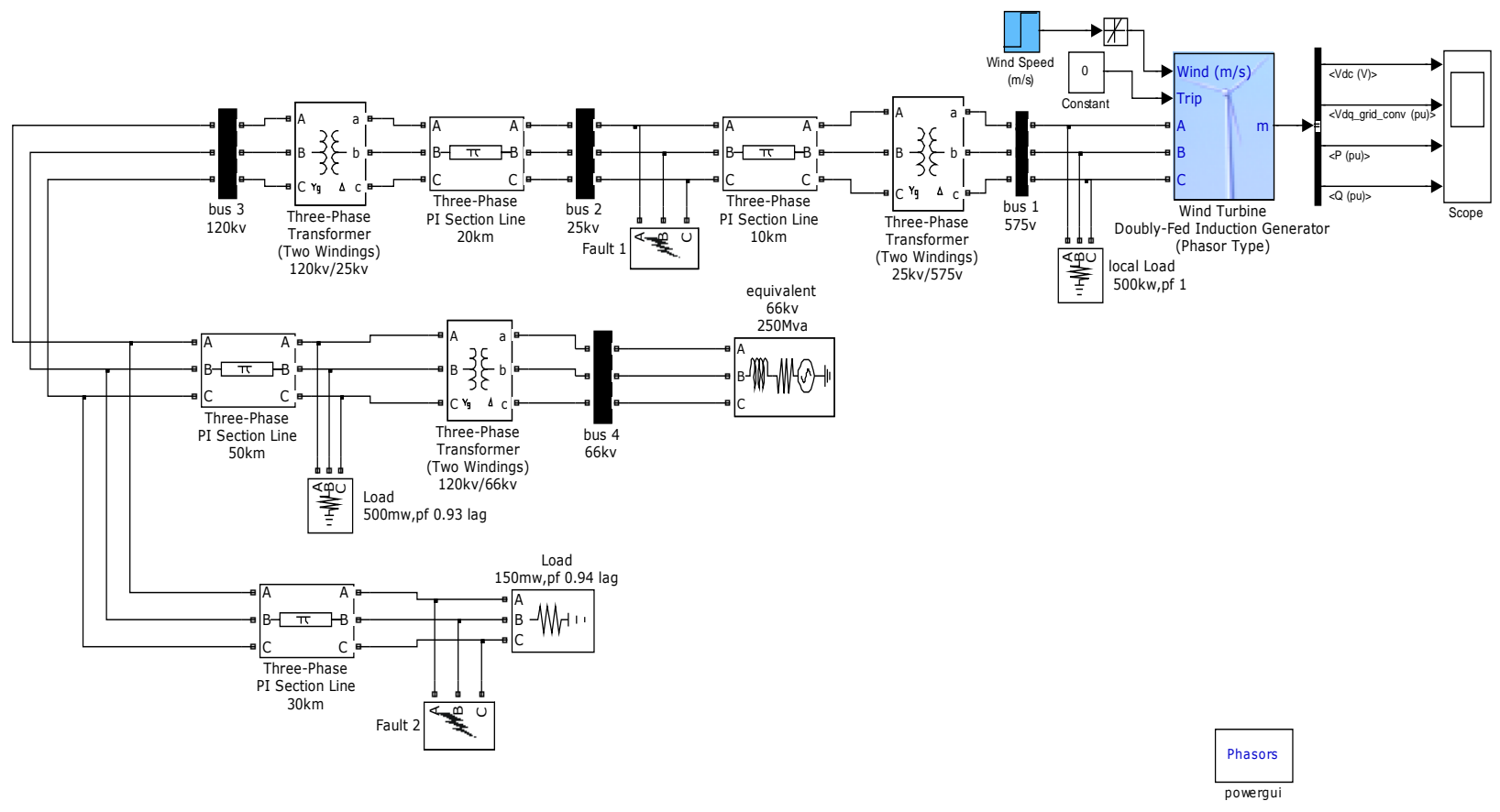

Figure.6.1. SIMULINK model of wind turbine grid connection

the DG can be demonstrated using the experimental data and the simulation data.

A simplified power system model with the wind turbine connection is shown in Figure 6.1. The SimPower Systems toolbox in MATLAB/SIMULINK is used to conduct the simulation. The Power System Blockset (PSB) in the SimPower System toolbox is developed in the graphical SIMULINK environment of the general purpose MATLAB software. The PSB is suitable for the simulation of electric circuits, power systems, power electronic devices, and electric drives.

It contains a block library with common components and devices available in electrical power systems based on electromagnetic and electromechanical equations.
The PSB/SIMULINK can be used for modelling and simulation of the power systems. The SIMULINK solves the system equations based on state-variable analysis using either a fixed or a variable time step. The converter is included in the wind turbine module to synchronize with the gird. 


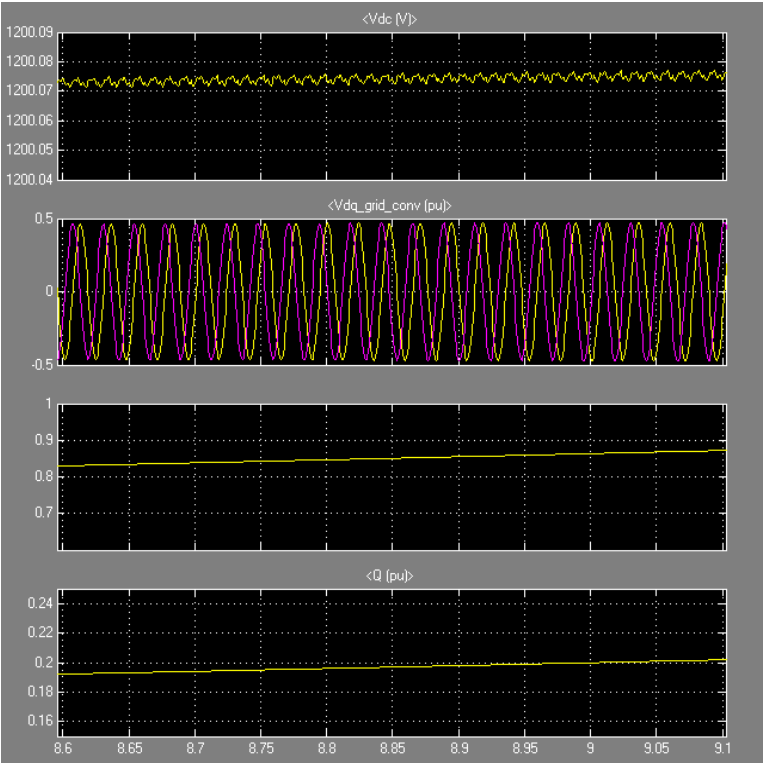

Figure.6.2. SIMULINK result of wind turbine grid connection

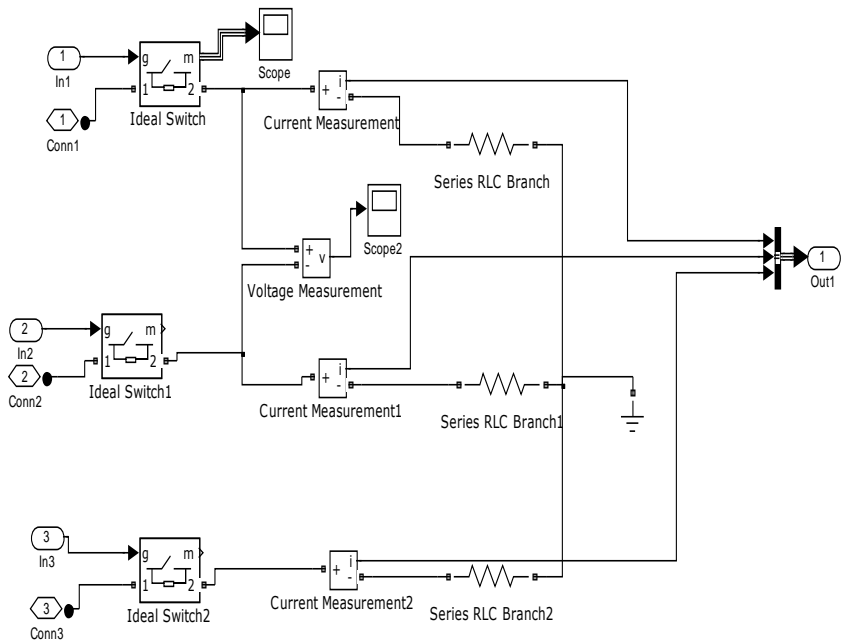

Figure.6.3. The detailed Crow-bar protection block

\subsection{Wind Electric Energy Simulation with Crow-Bar Protection}

A simplified power system model of wind turbine crow-bar protection is shown in Figure 6.4. The SimPower Systems toolbox in MATLAB/SIMULINK is used to conduct the simulation. The Asynchronous Machine Block in the SimPower System toolbox is developed in the graphical SIMULINK environment of the general purpose MATLAB software. The machine is connected to a subsystem block of crow-bar (Figure.6.3) which is shown below.

The wind speed is considered as a variable function with time; as a result, generated power from the wind turbine is also a variable function with time.

\subsubsection{Subsystem Block of Crow-Bar}

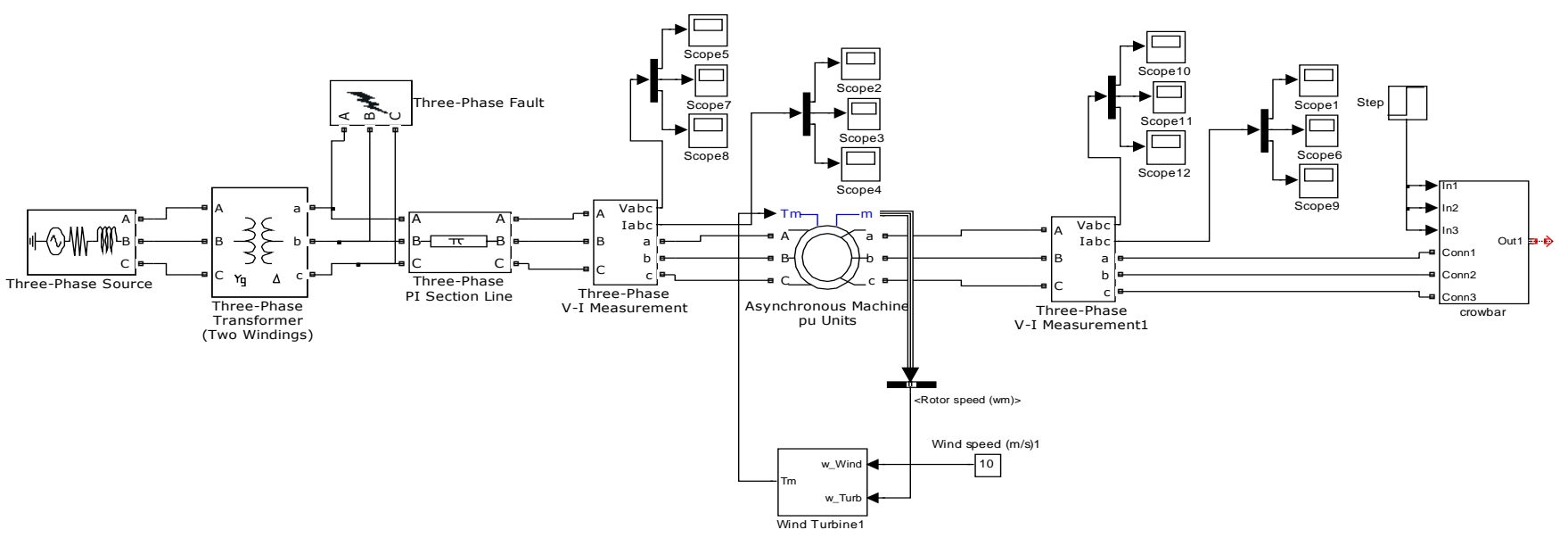

Figure.6.4. SIMULINK model of wind turbine crow-bar protection

\section{CONCLUSION}

This important area of work has been responsible for a steady improvement of both design and manufacturing quality and will help the industry move from its early pioneering stage to a competitive industry which can compete on a worldwide market. There is increasing use of variable speed systems. This will be the next major step for the technology and will result in a dramatic increase in potential. Careful consideration of the interaction between wind turbines and the grid is now, and will continue to be, an important area of both technical design and political action. It must be 
carefully sustained and is set to play a major role in future technology development.

The FRT assigns a crowbar resistance to be connected across the rotor terminals during the fault. The rotor-side converter is employed along with the grid-side converter to fed reactive current to the grid during the fault. The crowbar limits the generator currents to their rated values and completely protects the DC link and the converters by separating from rotor terminals. The voltage performance is enhanced and the recovery becomes faster. This is reliable and is considered as an adequate solution to keep the DFIG on during sharp voltage dip disturbances occurred outside its protection zone.

\section{ACKNOWLEDGMENTS}

We would like to articulate our gratitude to Prof.S.Jaganathan, Department of Electrical and Electronics Engineering for his invaluable suggestions and great encouragement all through this paper work.

\section{REFERENCES}

[1] H'ector, A., Pulgar-Painemal and Peter Sauer, W., 2009, "Dynamic modeling of wind power generation", IEE Proceedings: Generation, Transmission and Distribution, vol. 142, no. 5, pp. 545-551.

[2] Ali Kasem, H., Ehab El-Saadany, F., Hassan ElTamaly, and Mohamed Wahab,A.A. 2007, "A New Fault Ride-through Strategy for Doubly Fed WindPower Induction Generator", IEEE Canada Electrical Power Conference, ISBN 1-4244-1445-8.

[3] Golait, N., Moharil, R.M., Kulkarni, P.S.2009, "Wind electric power in the world and perspectives of its development in India," Renewable and Sustainable Energy Reviews, vol. 13, pp. 233-247.

[4] Mayurappriyan, P.S., Jovitha Jerome, Ramkumar, M., Rajambal, K. November 2009. "Dynamic Modeling and Analysis of Wind Turbine Driven Doubly Fed Induction Generator", International Journal of Recent Trends in Engineering, vol. 2, No. 5, pp.257-262.
[5] Elkington, K., Knazkins V., Ghandhari, M. 2007, "Modal Analysis of Power Systems with Doubly Fed Induction Generators", iREP Symposium - Bulk Power System Dynamics and Control - VII, Revitalizing Operational Reliability.

[6] Sudrià, A., Chindris, M., Sumper, A., Gross,G., Ferrer, F. 2007, "Wind Turbine Operation in Power Systems and Grid Connection Requirements", IEEE Power and Energy Magazine, vol. 5, no.6, pp. 47-51.

[7] Yazidi, A., Henao, H., Capolino, G.A., Casade, D., Filippetti,F. 2005. "Simulation of a Doubly-Fed Induction Machine for Wind Turbine Generator Fault Analysis", IEEE Transactions On Power Systems, ISBN 07803-9124-1.

[8] Yvonne Coughlan, Paul Smith, Alan Mullane, and Mark O'Malley, August 2007, “Wind Turbine Modelling for Power System Stability Analysis-A System Operator Perspective" IEEE Transactions On Power Systems, vol. 22, no. 3.

[9] Dawei Xiang, Li Ran, Peter Tavner, J.,Shunchang Yang, 2006, "Control of a Doubly Fed Induction Generator in a Wind Turbine During Grid Fault RideThrough", ISBN 0885-8969.

[10] Erlich,I., Kretschmann, J.,Mueller-Engelhardt, S. Koch, F., Fortmann, J. 2008,"Modeling of Wind Turbines based on Doubly-Fed Induction Generators for Power System Stability Studies", IEEE Transactions on Power Systems , Vol. 22, pp. 910917 